\title{
AS MUDANÇAS PSICOSSOCIAIS DO INDIVÍDUO NA TERCEIRA IDADE SOB A INFLUÊNCIA DAS RELAÇÕES INTERPESSOAIS ${ }^{1}$
}

\author{
THE INFLUENCE OF RELATIONSHIP AND \\ ITS PSYCHOSOCIAL CHANGING IN THIRD AGE PEOPLE
}

Locimara Ramos KROEF ${ }^{2}$

\begin{abstract}
RESUMO
Este estudo inclui uma pesquisa com sujeitos maiores de 60 anos, participantes de três grupos de convivência para idosos na cidade de Porto Alegre/RS/ Brasil. Investigou-se como o inter-relacionamento grupal influencia nas mudanças da vida na velhice, nas relações dos grupos e dos indivíduos com a sociedade. Nestes sujeitos, constatou-se uma procura de estímulo externo (grupos) para serem socialmente reativados, cujo processo disparador foi a indignação com a solidão, improdutividade mental, física e relacional gerada pelas perdas: aposentadoria, viuvez, ausência dos filhos, etc.
\end{abstract}

Palavras-chave: terceira idade; mudanças psicossociais.

\section{ABSTRACT \\ THE INFLUENCE OF RELATIONSHIP AND ITS PSYCHOSOCIAL CHANGING IN THIRD AGE PEOPLE}

This search includes a research with the third age (more than 60 years old), in 3 different acquaintance groups in Porto Alegre city, Rio Grande do Sul state, south of Brazil. The influence of the groupal relationships in the changes of the elders lives was observed, with the encrease of new relationships. These

\footnotetext{
(1) Dados sobre este trabalho, com o mesmo título, foram apresentados na condição de Temas Livres p.69 do XI Congresso Brasileiro de Geriatria e Gerontologia de 5 a 9 de dezembro de 1997.

(2) Locimara Ramos Kroeff, Graduada e Licenciada em Psicologia na UFRGS, Psicóloga da Universidade para a Terceira Idade de UFRGS.

Endereço para correspondência: Rua José Garibaldi, 1628, CEP: 94425000

Viamão-RS Fones: (051)4853057 e (051)9603636 E-mail: locirk@vortex.ufrgs.br

Órgão financiador: Fundação de Amparo à Pesquisa do Rio Grande do Sul (FAPERGS)

Orientador da pesquisa:Sergio Antonio Carlos, Doutor em Serviço Social, professor adjunto do Departamento de Psicologia Social e Institucional da UFRGS.
} 


\begin{abstract}
people seeked new stimuli in other to cape with distress caused bylonelyness, security pensions, windowhood and lhe loss of their children.

Key words: third age people, psychosocial changes
\end{abstract}

\section{INTRODUÇÃO}

Nos últimos anos a sociedade tem se dedicado aos idosos devido o "problema" do aumento desta população. Assim, a política social construída, até então, para uma população especificamente jovem é discriminadora com relação ao velho e ineficiente para lidar com a situação futura que prevê uma população significativamente mais envelhecida.

Segundo Salgado (1979), a marginalização social do idoso é traduzida, especialmente, pela falta de participação no processo de integração na sociedade, sendo que a marginalização se caracteriza como uma situação oposta à integração social. Portanto, os programas e projetos para a terceira idade, lançados no meio social, podem representar um reengajamento social para receber e atender o idoso desengajado na sociedade devido a ausência de preparação para a aposentadoria, Assim, questiona-se este processo dialético do idoso se desengajar (Salgado, 1979), como cidadão e se engajar no sistema marginalizador, sendo que há, também, a oportunidade de produzir, num processo de contra cultura, um novo engajamento social.

Através do saber adquirido, pode-se realizar uma reformulação no contexto social e pessoal da velhice, trazendo uma prevenção mais eficiente para evitar o agravamento dos problemas próprios do envelhecimento. Neste sentido, a presente pesquisa objetivou, com o estudo sobre as relações dos grupos e dos indivíduos com a sociedade, estudar a influência das relações interpessoais nas mudanças pessoais investigando como o inter-relacionamento grupal atua numa possível alteração social em relação a velhice. Buscou-se avaliar tanto os aspectos gerais do grupo em estudo como os aspectos individuais de cada sujeito selecionado dos grupos, fazendo uma integração, e identificar os tipos de mudanças que se estabeleceu na vida do idoso: se intervém trazendo mudança, não só no comportamento, mas inclusive, nos paradigmas do indivíduo, verificando até que ponto os problemas são solucionados ou deslocados e o quanto essas mudanças significam ou não uma alteridade (Querolin, 1994) na vida pessoal e social.

\section{METODOLOGIA}

A pesquisa foi realizada em três grupos de convivência de terceira idade de Porto AlegreRS. Realizou-se 101 visitas para entrevistas, observações das atividades dos grupos e aplicação de um questionário para traçar o perfil tanto dos grupos quanto dos sujeitos. O questionário foi respondido por dez sujeitos de cada grupo, perfazendo 30 sujeitos. Foram selecionados tendo como critérios a frequência ao grupo há pelo menos um ano. Destes, selecionou-se, para a amostra $A$, quatro participantes de cada grupo estudado (totalizando doze sujeitos), afim de realizar entrevistas semi dirigidas.

\section{Perfil dos Grupos}

\section{Grupo 1}

Se caracteriza por pertencer a comunidade de um bairro de Porto Alegre. O Centro Comunitário, ao qual está ligado, existe há 50 anos, possui em torno de 190 participantes com mais de 50 anos de idade e é gratuito. Este grupo funciona com uma presidente, uma vice presidente, um conselho administrativo e fiscal.

Objetivos: promover as relações sociais, a participação dos idosos em eventos culturais e proporcionar o acesso às informações e ao conhecimento.

Atividades: orientação sócio familiar, palestras mensais, bocha, bailes semanais (esti- 
ma-se de 80 a 100 freqüentadores, onde o número de homens e mulheres está mais equilibrado), ginástica, artesanato, fisioterapia e o grupo de convivência (de 5 a 30 mulheres; nestas programações raramente aparecem homens).

Na coordenação geral estão funcionários da FESC (órgão municipal) que definem a programação básica a ser desenvolvida no decorrer do ano para o grupo.As reuniões administrativas do grupo são divididas em técnicas (funcionários da FESC) e da diretoria (funcionários da FESC, presidência e conselho do grupo).

Nos bailes é liberada a venda de bebidas alcoólicas. Também são vendidos salgados, sendo que as quituteiras pertencem ao grupo. $O$ dinheiro arrecadado é somente da copa dos bailes e de chás organizados pelo próprio grupo e serve para comprar material como equipamento de som, frizer, etc. O som mecânico tem como repertório músicas de fandango, sendo administrado por funcionários da FESC. Há também uma banda de samba ao vivo constituída por homens componentes do grupo. Apesar dos freqüentadores do grupo pertencerem, a maioria, a uma camada social de baixo poder aquisitivo, percebe-se um forte preconceito contra aqueles que não se preocupam com a aparência: estarem vestidos de acordo para o baile e limpos, como por exemplo quando um homem chega da cancha de bocha de abrigo e empoeirado para o baile, geralmente é barrado ou chamam-lhe a atenção.

\section{Grupo 2}

Está constituído dentro de um Clube freqüentado pela alta sociedade de Porto Alegre. Portanto, trata-se de uma instituição paga constituída de associados. Conta com 60 mulheres inscritas no grupo e mais simpatizantes. Este grupo existe há 10 anos.

Objetivo: é o lazer, buscando, através deste, melhorar a qualidade de vida.

Atividades: coral, curso de dança (pagode, com 100 alunas), chás com baile mensal (em torno de 180 participantes), almoços, passeios, viagens eventuais, intercâmbio com outros grupos.

Este grupo de terceira idade se constitui como um dos departamentos do clube e possui diretora, vice-diretora, tesoureiro, secretária, relações públicas, rainha, 2 princesas e grupo de apoio (totalizando 20 das 60 integrantes). 0 grupo também possui um estatuto cujas alterações no mesmo dependem da aprovação do conselho do clube. Em geral, a presidência do clube apoia todas as decisões e idéias da diretora do grupo e dá ao grupo total autonomia para se encaminhar.A presidência, assim como as diretorias do clube trocam de 2 em 2 anos, sendo as diretorias indicadas pela presidência.

A idade mínima seria 60 anos, mas como pessoas em torno de 50 anos procuram o grupo é permitida a adesão das mesmas. Não existe cobrança de presenças com total liberdade de escolha de ir e vir das integrantes e participantes.

A diretoria organiza passeios para águas termas e uma vez por ano viajam ao exterior. Nos chás com baile cobra-se um ingresso, no entanto, as 60 associadas do grupo são isentas. É rara a presença de homens. Eles não estão inscritos, mas, como o grupo é aberto aos sócios idosos do Clube, os homens participam eventualmente em atividades como almoços e festas. O baile tem som mecânico, tendo como repertório pagode, axé music e músicas alemãs. Algumas integrantes comentam que, quando começaram a freqüentar o grupo, estranhavam ou achavam esquisito o fato das mulheres tirarem outras para dançar. Agora, dizem que se acostumaram e aderiram com facilidade.

As palestras são dispensadas, pois dizem não querer saber sobre doença e as sugestões dos integrantes do grupo se restringem às atividades de lazer. Observa-se um discurso geral dos idosos no Grupo de não comentarem transtornos ou problemas de suas vidas pessoais. Há uma rejeição às queixas, e cultuam o pensamento positivo. Tais atitudes e verbalizações 
estão representadas como um pacto de só se falar em coisas alegres, ficando implícito que aqueles que não cumprem esse pacto ficam mais a margem do grupo. Como exemplo, heis um caso de uma componente que estava preocupada e deprimida com um problema de saúde do qual foi vítima, sendo obrigada a largar algumas atividades. Durante um determinado evento do grupo só ela se encontrava sozinha numa mesa, algumas se aproximavam e falavam com ela superficialmente, pois sempre comentava o seu problema. Todos a tratavam muito educadamente, mas ninguém estava disposto a ouvir as suas "lamúrias". Ela acabou indo embora mais cedo.

\section{Grupo 3}

Caracteriza-se por pertencer a uma Universidade Pública. $O$ grupo existe há 7 anos. Além do grupo de terceira idade, o idoso obtém como identidade ser aluno da Universidade.Os participantes estão, predominantemente na faixa de 60 a 75 anos, residentes, a maioria, em Porto Alegre e alguns na grande Porto Alegre, sendo mais de $90 \%$ do sexo feminino.Quanto a escolaridade apresenta uma maioria de sujeitos com segundo e terceiro grau.

Objetivos: resgate da cidadania e exercício da autogestão nos grupos.

Atividades: artesanato, teatro, ioga, coral, grupo comunitário, línguas, fitoterapia, ecologia, etc.

O funcionamento deste grupo consiste em reuniões semanais com todos os seus participantes, em torno de 130, e atividades em subgrupos: oficinas e/ou grupos de interesses. Nos encontros semanais são realizadas palestras e painéis sobre temas de interesse do grupo. Tal grupo funciona como um "pólo irradiador" de onde derivam os subgrupos.

Os subgrupos diferenciam-se pelo interesse central de seus participantes. Os grupos de desenvolvimento interpessoal voltam-se primordialmente para o próprio sujeito na relação com os seus pares, enquanto os grupos de interesses demonstram também um envolvimento com as questões comunitárias, funcionando como elementos multiplicadores. Pode-se diferenciar tais grupos conforme Lewin (apud Hagemann, 1977:47), classifica: "Psicogrupo: centrado em si mesmo - objetivo: próprio crescimento e Sócio-grupo: voltado para a realização de tarefas (fábrica, sala de aula, etc.)". Assim, podemos definir nesta instituição os grupos de interesse como sócio-grupo e os grupos de desenvolvimento interpessoal como psico-grupo. Os subgrupos tem encontros periódicos (uma vez por semana), sistemáticos (durante o semestre) e com dia e hora prédeterminados. Os grupos de desenvolvimento interpessoal são coordenados por um(a) psicólogo(a) ou estagiário(a) de psicologia. Os subgrupos são coordenados pelos próprios usuários atendendo a um princípio de autoreferência e autogerenciamento promovido pela instituição, dentro da ideologia da autogestão, sendo constituídos autonomamente pelos seus participantes.

\section{ANÁLISE DOS RESULTADOSOBTIDOS}

A diferença da dinâmica dos grupos estudados baseou-se na instituição de origem a qual estava subordinado, determinando dependência relativa às ideologias pertinentes a cada grupo.

A maioria das atividades no grupo 3 eram coordenadas pelos participantes do grupo gratuitamente, enquanto nos grupos 1 e 2 eram coordenadas por profissionais contratados ou estagiários.

Na dinâmica da organização na condução das atividades, os grupos 1 e 2 se assemelhavam por não cobrarem assiduidade e participação dos componentes, sendo que ambos abriam espaço para participar e assumir tarefas. Apesar de não haver cobrança de presença dos integrantes nas atividades, nem tão pouco inscrição nas mesmas, estes grupos se mantinham organizados. 
Todos os grupos apresentavam segurança na organização e condução das atividades. O grupo 3 diferenciou-se por privilegiara busca do conhecimento, valorizando atividades voltadas para a comunidade e cobrava assiduidade e comprometimento dos seus integrantes.

O grupo 2 adaptou-se às circunstâncias do próprio grupo através de um novo costume (dança de pares femininos), que as próprias idosas criaram pela falta da figura masculina $e$ pela necessidade de se divertir dançando, que se caracteriza como totalmente oposto aos costumes implementados durante a juventude e vida madura dessa geração onde os bailes eram caracterizados pela dança de pares (homem com mulher).

Nos grupos 1 e 3 observou-se uma tendência dos idosos pedirem aos funcionários ou coordenadores que fizessem as tarefas por eles, buscando uma dependência e responsabilizando o outro pelo desfecho das decisões. No grupo 3, apesar da ideologia do autogerenciamento, observou-se que a maioria dos participantes tendem a atribuir as decisões para os coordenadores. Assim, o idoso livrava-se de desafiar a sua competência e testá-la, buscando uma dependência no funcionário que seria o responsável se as coisas não acontecessem.

Identificou-se, portanto, uma resistência destes idosos para sair da posição de sujeitado (Foulcault, 1992), repetindo comportamentos de submissão. Mesmo com a proposta de intervenção psicossocial para reconstruir um modo de relação grupal mais participativo e menos centrado em determinadas pessoas, percebeu-se no grupo 3 que, às vezes, a própria coordenação da instituição entrava num jogo. contraditório, atendendo ao apelo do grupo por um dirigente com maior poder decisório.
Constatou-se que determinadas mudanças significavam uma alteridade (Querolin, 1994) na vida pessoal do idoso, enquanto outras significava uma mudança aparente socialmente. No grupo 2 a mudança aparente foi flagrada na contradição sendo que, ao determinarem a "regra" básica de só se falar em coisas alegres, admitiam que existem problemas, porém, esses deveriam ser negados no grupo. O grupo se eximia da função de participar desses problemas - isso era delegado para qualquer outra instância que também não seria de sua conta. Aqui pode-se constatar o que Watzlawick et alli (1973), identificou como mudança de $1^{\text {a }}$ ordem, pois o comportamento de alegria e contentamento do grupo apareceu como opositor aos infortúnios da vida e aos problemas, porém, esses nãosendo resolvidos continuavam latentes, apesar da "máscara" colocada omitindo-se ou rejeitando-se tais problemas no grupo.

A pesquisa nos grupos permitiu verificar a valoração fundamental que a maioria dos idosos colocavam nas relações interpessoais proporcionada pelos grupos, pois a representação do grupo pode ser comparada com a representação que o trabalho ou a família tiveram em suas vidas.

Identificou-se, que o movimento pessoal, inter-relacional e grupal reflete uma possível alteração social em relação a velhice. Os dados obtidos indicaram alterações na forma do idoso se relacionar em áreas categorizadas como: familiares, financeiras, sociais, físicas e pes-soais.

A aplicação do questionário permitiu a elaboração de tabelas comparativas expostas abaixo com os dados mais relevantes.

As diferenças no poder aquisitivo dos grupos:

Tabela 1 - percentagem salarial

\begin{tabular}{|c|c|c|}
\hline $\mathrm{G} 1=1 \mathrm{a} 4 \mathrm{sal}=92 \%$ & $\mathrm{G} 2=10$ ou mais sal $=100 \%$ & $\mathrm{G} 3=1 \mathrm{a} 4 \mathrm{sal}=12 \%$ \\
\hline $\mathrm{G} 1=5 \mathrm{a} 9 \mathrm{sal}=8 \%$ & & $\begin{array}{l}\mathrm{G} 3=5 \text { a } 9 \text { sal }=68 \% \\
\text { G3 }=10 \text { ou mais }=20 \%\end{array}$ \\
\hline
\end{tabular}


Quanto a escolaridade os grupos 1 e 2 tinham instrução equiparadas, apesar da gran- de diferença no poder aquisitivo e o grupo 3, apresentou o mais alto nível de instrução:

Tabela 2 - grau instrução dos grupos

$$
\begin{array}{l|l|l}
\hline \mathrm{G} 1=1^{\circ} \mathrm{grau}=74 \% & \mathrm{G} 2=1^{\circ} \mathrm{grau}=68 \% & \mathrm{G} 3=1^{\circ} \mathrm{grau}=14 \% \\
\mathrm{G} 1=2^{\circ} \mathrm{grau}=24 \% & \mathrm{G} 2=2^{\circ} \mathrm{grau}=28 \% & \mathrm{G} 3=2^{\circ} \mathrm{grau}=44 \% \\
\mathrm{G} 1=3^{\circ} \mathrm{grau}=2 \% & \mathrm{G} 2=3^{\circ} \mathrm{grau}=4 \% & \mathrm{G} 3=3^{\circ} \mathrm{grau}=42 \%
\end{array}
$$

O dado acima talvez possa representar que a classe média valorizava mais a busca do conhecimento, a cultura, enquanto as limitações da classe baixa não permitiam este tipo de preocupação, e na classe alta, que por essência é capitalista, a preocupação principal para a geração destes idosos sempre foi a aquisição de bens materiais.

Outra diferença marcante nestes grupos foi a participação dos homens nos eventos sociais conforme os dados obtidos:

No grupo 1, que tem menor poder aquisitivo, as mulheres tinham mais companheiros a disposição para as festividades. Nos grupos 2 e 3 era mais raro. Suponde-se que nos grupos com melhor condição financeira hajam homens de negócio que tendem a se aposentar mais tarde. Além disso, o poder aquisitivo dos idosos pertencentes a classe social do grupo 2 poderia proporcionar um leque maior de oportunidades, de relações e opções de programas sociais e de lazer, somando-se a isso a crença cultural de que, em geral, os homens velhos abastados buscam se relacionar com mulheres mais jovens. Portanto, era mais comum ver as mulheres do grupo 1 acompanhadas de maridos ou namorados. No grupo 2, até as casadas estavam raramente acompanhadas pela figura masculina nas programações festivas.
Os depoimentos dos idosos, indicaram uma busca de estímulo externo para tornaremse socialmente mais ativos, sendo os grupos contribuidores para a reatividade nestes sujeitos. Assim, tornaram-se socialmente mais atuantes pelo estímulo proporcionado pelo ambiente grupal. Conclui-se que, ao procurar os grupos de terceira idade, o idoso já havia implementado uma mudança de atitude. O processo disparador para esta mudança foi a indignação do velho com a situação de solidão, de improdutividade mental, física e relacional em que caiu pela aposentadoria, perda do cônjuge, ausência dos filhos e/ou pelo próprio envelhecimento físico. Os depoimentos dos sujeitos da amostra Adenotam que eles mesmos entraram nos grupos com o propósito de reagirem diante de determinada situação que estavam vivenciando:

"Perdi meu marido por causa de um ataque cardíaco que teve quando o seu time de futebol perdeu... Morreu por causa de uma bobagem... Depois disso o meu filho mais velho se suicidou por causa da morte dopai... Foi por isso que vim parar aqui "(no Grupo) - Maria, 72 anos.

"Fui trazida por uma amiga, estava muito solitária, parada, então ela me trouxe pra cá. Antes outras já tinham me convidado, mas eu achava bobagem, não fazia a minha cabeça. $A$ primeira vez que vim para $o X$ (grupo) fiquei chocada, achei deprimente aquela velharia... Aí eu me dei conta que também estava velha como eles.... Depois acostumei e achei legal'- Tereza, 61 anos. 
Quanto a melhor qualidade de vida, uma vida que seja alegre, além de saudável, estar intimamente vinculada com uma melhor produtividade e menor índice de estados de doença, os depoimentos abaixo dos sujeitos da amostra A versam sobre esta questão:

"Eu admiro esta senhora, ela teve um ataque cardíaco, depois um tumor no cérebro, ficou careca, perdeu os movimentos e não desistiu do grupo... Ela faz ginástica, se esforça e quem olha não diz que já aconteceu tudo isso com ela"- Leda, 65 anos.

"Fulana fala assim por causa de um derrame cerebral, agora ela ta aprendendo a falar de novo e nunca falta a aula e tá sempre trabalhando"(no grupo) - Zilla, 63 anos. Ambas as vítimas dos eventos citados nos depoimentos referem pessoalmente que o grupo e as amizades ajudam-nas muito a reagir, "dão força".

As doenças físicas e mentais na velhice passam a ser encaradas, embora ainda com surpresa, como nas etapas anteriores da vida: na maioria das suas enfermidades os idosos passam a ser recuperados, tratados e também curados. O ciclo velhice, doença e morte, logicamente estereotipado, torna-se ultrapassado diante da longevidade viável no ser humano.

\section{CONSIDERAÇÕES FINAIS}

Os resultados obtidos nesta pesquisa são suficientes para mostrar que as relações interpessoais, promovidas nos moldes dos grupos investigados, influenciam profundamente numa reformulação social e pessoal da velhice impedindo que os idosos se tornem propensos a ficarem marginalizados socialmente.

O grupo surge, então, como um lugar onde o idoso terá espaço para produzir mudanças na sua vida e desse retirará o apoio para suas transformações serem aprovadas social-mente, incluindo o meio familiar. A partir do grupo, o idoso segue introduzindo novos costumes, valores, hábitos, idéias em sua vida. $\mathrm{O}$ relacionamento interpessoal criativo, afetivo $e$ efetivo (Kroeff \& Schneider, 1998), seja com o grupo ou/e com a família torna-se fundamental e necessário para aumentar as possibilidades de mudanças e aprimorar a qualidade de vida do velho.

Portanto, os grupos de idosos tornam-se socialmente necessários, no sentido de aproveitar o insight do velho em determinado momento de sua vida, afim de resgatar a qualidade de vida e transformar estigmas viciados em torno do envelhecimento. Por isso, o apoio da sociedade para os grupos de terceira idade torna-se de fundamental importância para a saúde pública, partindo-sedo pressuposto que saúde é tanto física como mental.

Junto ao aumento do envelhecimento da população mundial os valores e conceitos com relação a velhice passam por uma forte transformação social, profundamente sentida pela presente geração de avôs e avós e conflituada devido ao despreparo para a realidade social atual. Entretanto, a reeleitura globalizada sobre o envelhecimento, que oportuniza ações preventivas, fornecerá subsídios para a construção de um novo modo de viver a velhice para as gerações futuras.

\section{REFERÊNCIAS}

BARBIER, R. (1985). Pesquisa-ação na instituição educativa. Rio de Janeiro:

Zahar, 39-165.

BARDIN, L. (1979). Análise de conteúdo. Lisboa: Edições 70, 225.

FOULCAULT, M. (1992). Microfísica do Poder. Rio de Janeiro, Graal, 210-248.

HAGEMANN, L; Pinhal, M. A.; Silva, M. S.; Carlos, S. A. (1977). A teoria

psicológica de Kurt Lewin. Porto Alegre, Cursos de Pós Graduação em

Educação, UFRGS, 47. 
KROEFF, L. R. \& Schneider, A. (1998). O idoso e o vínculo institucional. Velhice que idade é esta? Porto Alegre, Síntese, 141-151.

QUEROLIN, L.(1994). Psicoterapias - independência ou subordinação!? CFP:Almanaque, Ano IX, no 36 .

SALGADO, M. A. (1979). Gerontologia social. Rio de Janeiro: CBCISS(cadernos verde), no 150 .
SEVERINO, A. J. (1989). Metodologia do trabaIhocientífico. 15 ed. São Paulo:Corteze Autores Associados, 238.

VERAS, R. P. (1994). País de jovem com cabelos Brancos: a saúde do idoso no Brasil. Rio de Janeiro: Dumará, 168-180.

WATZLAWICK, P. et alli.(1973). Mudança: princípios de formação e resolução de problemas. São Paulo: Ed. Cultrix, 19-100. 